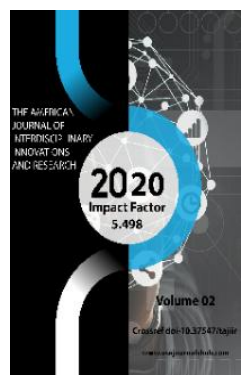

\section{Structural Transformations Of The Economies Of The Regions Of Uzbekistan}

\author{
Asadov Hurshed Sa'dullaevich \\ Independent researcher of the National University of Uzbekistan named Mirzo Ulugbek, \\ Uzbekistan
}

Journal Website: http://usajournalshub.c om/index,php/tajiir

Copyright: Original content from this work may be used under the terms of the creative commons attributes 4.0 licence.

\title{
ABSTRACT
}

This article describes the current structural changes in the regional economy and their impact on the formation of a stable economic growth of the gross regional product, as well as the quality of economic growth. Based on the results of the analysis, measures are proposed to achieve effective structural transformations of the economies of the regions.

\section{KEYWORDS}

Regions, economic growth, structural shifts, the quality of economic growth, the gross regional product.

\section{INTRODUCTION}

The state of the structure of the economy plays an irreplaceable role in ensuring the balance of the region's economy, in the formation of sustainable rates of economic growth, in stimulating the diversification and localization of production, which in turn determines the prerequisites for the growth of the competitiveness of the economy. These targets were declared in several regulatory legal acts adopted by the President of the Republic of Uzbekistan Sh. Mirziyoyev over the past years, which include the Decrees of the President of the Republic of Uzbekistan dated February 7, 2017 No.4947 "On the strategy of actions for the further development of the Republic of Uzbekistan" [ 1], dated September 8, 2017 No.5185 "The concept of administrative reform in the Republic of Uzbekistan" [2], Resolution of the President of the Republic of Uzbekistan dated August 8, 2017 No.3182 "On priority measures to ensure accelerated socio-economic development of regions" etc.

The very definition of the structure of the economy can be considered as a 
multidimensional phenomenon and it can be studied from different conceptual positions, showing the relationship between various elements of the economic process [4].

The characteristic of structural changes in the economic development of regions is reflected in the changes of the qualitative indicators of the economy, where the results of structural changes are manifested in structural shifts.

Structural shifts or changes are determined in the process of observing the structure of the economy in a certain period (in dynamics) [5].

Structural shifts in the economy represent a complex system of changes in interrelated proportions that occur under the influence of the existing technological base, social mechanisms of production, distribution and exchange under regional needs, available resources and the achieved level of labor productivity.

Literature review. The analysis of structural changes in the regional economy first of all helps to determine the state of the regional economy and the determinants of its economic growth. Moreover, by analyzing the structure of the regional economy, one can determine their competitive advantages in interregional comparison and the specialization of the regional economy [6].

Based on the study of the literature on structural changes, it can be concluded that the concept of the structure of the regional economy is a set of system elements, complex relationships and relationships between the economic processes of enterprises, industries and types of economic activities in the economy of the region, between reproduction, investment, resource, financial, innovative and other processes that determine the integrity of the region's economy and the preservation of its basic properties and key functions under the influence of internal and external factors. The specificity, high-quality functioning and positive dynamics of the structure of the regional economy depend both on macroeconomic processes and the determination of strategic directions for the development of the region's economy, ensuring its balance and sustainable development.

Another important direction in the analysis of structural shifts in the sectors of the regional economy is to determine the effectiveness of the economic policy developed both at the national level and the level of local government bodies, its impact on the quality of economic growth by changing social conditions or improving the priorities of socially oriented policy in the region.

In the studies of L. Walras the problems of economic equilibrium were considered in conjunction with structural transformations while in D. Ricardo's, the dynamic processes of the structure of the economy were considered in conjunction with the problems of labor and profit. Moreover, the studies of M. Friedman and A. Marshall are devoted to the structure and dynamics of economic development. Studies conducted by S. Yu. Glazyev, A. G. Granberg, R.S. Grinberg, Yu. V. Yakovts and E. G. Yasin reveal the characteristics of structural processes, mechanisms of structural transformation of the economy and methodological problems of predicting structural dynamics in modern conditions. ...

According to the above studies, it can be concluded that, depending on the choice of structure-forming elements, one can talk about different typologies of the structure of the economy. The typology of the structure of the economy, based on their classification features, include reproductive, organizational and economic, technological, sectoral, socioeconomic and regional.

The reproduction structure acts as the ratio of the processes of production, distribution, 
exchange and consumption. The organizational and economic structure is characterized by the system of proportions between the parts of the social product created by the economic units, grouped by the level of specialization or concentration of production. The technological structure is revealed through the concept of "technological order". The sectoral structure implies the distribution of the shares of the gross product, national income, fixed assets between the spheres of production and sectors of the economy. The socio-economic structure is determined by the differentiation of incomes of various strata and groups of the population and the contribution of enterprises of various forms of ownership to the production of a social product. The regional structure of the economy is associated, first of all, with the solution of the following tasks of forming full-fledged economic complexes and business entities in all regions of the country, leveling the living conditions in the constituent entities.

Based on the above types of economic structures, it is necessary to single out the most effective and relevant ones which have the most significant impact on the qualitative dynamics of macroeconomic situation and, above all, on ensuring the competitiveness of the country's economy in the world, economic stability, energy efficiency and resource efficiency. Consequently, the sectoral structure is one of the most important components of the national economy and, above all, the sectoral structure is one of the key in the study of structural changes in the economy.

The sectoral structure of production reflects the existing system of distribution of production resources for key activities, as well as the share of individual sectors in the total volume of national production. The sectoral structure characterizes the composition, quantitative relations and forms of interconnection of industries and industries, the degree of differentiation and specialization of these industries and the features of economic interconnections and relations between them.

Analysis and results. Today it becomes obvious that the country's exit from the crisis, the implementation of effective structural changes in the national economy at all levels of the economic vertical, and the acceleration of scientific and technological progress depend on the quality of developments in the regions. The restructuring of the national economy vertically should be accompanied by the creation of an effective institutional management system, the formation of tools that stimulate the growth of the competitiveness of the national and regional economies, the improvement of the regulatory and legislative framework in the field of structural changes and investments, budget policy, and protection of property rights.

Improvement of management mechanisms, further integration of the national economy into the globalization processes of the world economy, as well as the large-scale reforms carried out during the years of independence to a certain extent influenced the structure of both the national economy and the regional economy. This is due to shifts in the structures of the regional economy over these years.

A purposeful regional policy has been pursued in Uzbekistan since the first days of independence. Deep institutional changes have been carried out, measures have been taken for the integrated development of the regions, and targeted comprehensive regional programs are being implemented. They make it possible to "improve the regional component of the economy, effectively use the available economic opportunities and unused resources, eliminate the existing regional imbalances, as well as the main 
problem of today - an effective fight against unemployment."

These measures are aimed at modernizing and diversifying the regional economies, increasing the level of competitiveness of the regional economies in world economic processes, ensuring stable economic growth, and, most importantly, achieving a high level of well-being of the population.

During this period, a number of measures were implemented that were enshrined in regulatory legal acts by the government of the country, in particular, the Decree of the President of the Republic of Uzbekistan dated December 15, 2010 No.1442 "On the priorities of industrial development of the Republic of Uzbekistan in 2010-2015" [7], Decree Of the President of the Republic of Uzbekistan dated March 4, 2015 No.4707 "On the program of measures to ensure structural changes, modernization and diversification of production for 2015-2019" [8], Resolution of the President of the Republic of Uzbekistan dated May 5, 2015 No.2343 “On The Program of Measures to Reduce Energy Intensity, Implementation of Energy-Saving Technologies in the Sectors of the Economy and Social Sphere for 2015-2019" [9], Resolution of the Cabinet of Ministers of the Republic of Uzbekistan dated January 5, 2016 No.3 "On measures to further improve the procedure for the development of urban planning documentation for the development and development of territories of cities and urban settlements"[10]. These measures significantly improved the economic situation in the regions by influencing the structures of the regional economies with an emphasis on more efficient production sectors.

The regulatory legal acts adopted by the government of the country served as the basis for economic diversification and led to structural changes in the sectors of the regional economy (see Picture 1).

Analysis, changes in the sectoral structure of the economy of the regions of Uzbekistan for 2000 - 2016 showed that over the entire analyzed period, in almost all regions of the country, the share of the industry in the formation of the GRP has significantly increased.

The analysis of the structure of the regional economy was carried out by applying the following formula:

$$
S_{i}^{r}=\frac{V A_{i}^{r}}{G R P^{r}} * 100,
$$

Where,

$S_{i}^{r}$ - the share of gross value added (GVA) of the i-industry of the $r$-region in the formation of the GRP of the r-region;

$V A_{i}^{r}$ - gross value added (GVA) of the i-industry of the r-region;

$G R P^{r}$ - GRP of r-region.

Picture 1. Structural changes in the sectoral structure of the formation of the GRP of the regions of Uzbekistan for 2000 -2019 (in\%) 


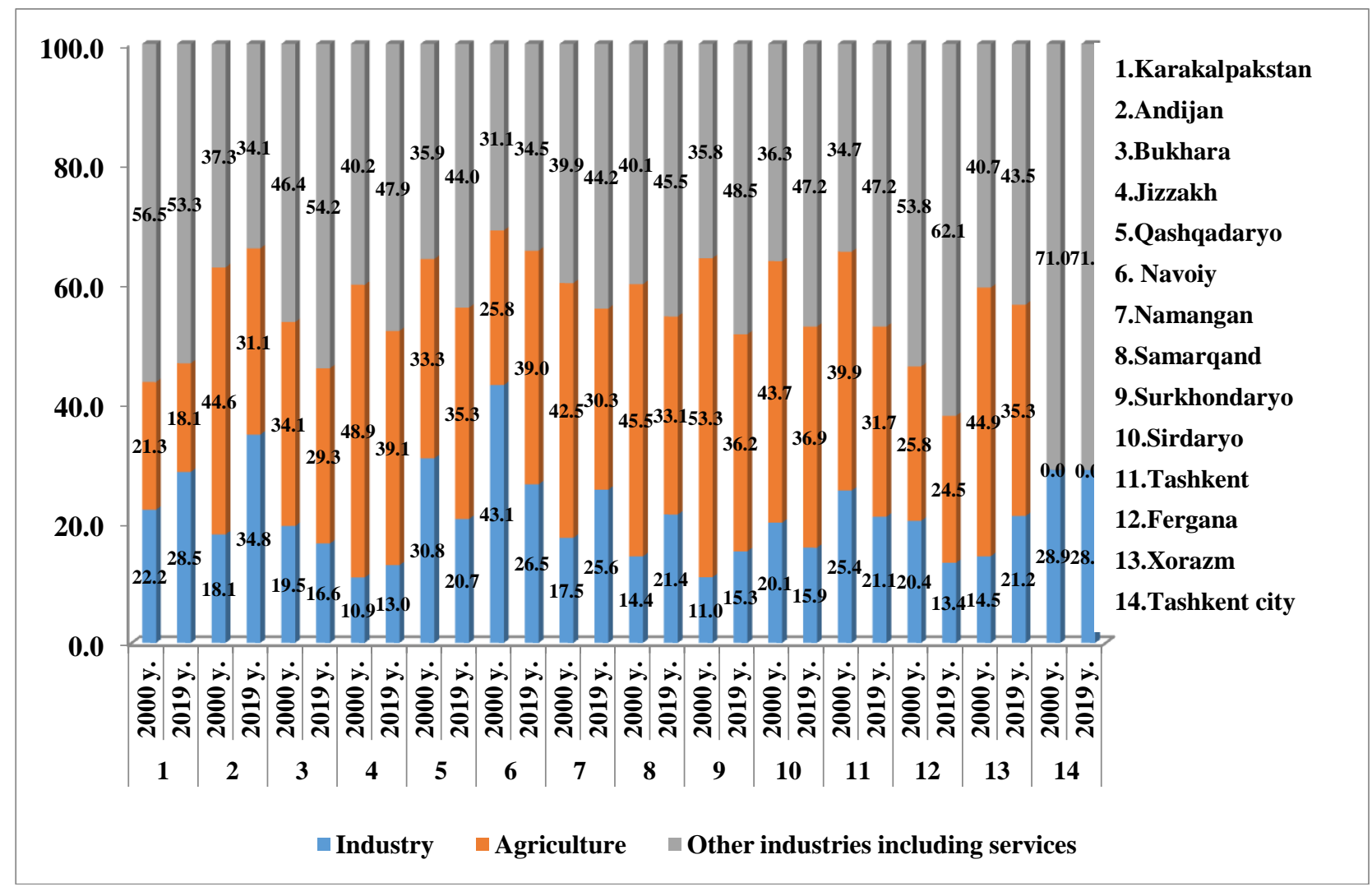

Source: Author's calculations based on data from the State Statistics Committee of the Republic of Uzbekistan. Data for 2000-2019 retrieved from the Statistical Yearbook.

Based on the results obtained by analyzing the sectoral structure of the regional economy, it can be concluded that the most positive structural changes have been achieved in such regions as Tashkent, Navoiy, Republic of Karakalpakstan, Andijan regions, and the city of Tashkent. Changes in the sectoral structures of the economies of other regions have deteriorated significantly compared to the existing structure of their economies in 2000.

However, the ongoing processes in the global economy, in light of the coronavirus pandemic and the associated instability of the price levels in world markets, as well as political disagreements between the leading states, the application of various restrictions in the form of economic sanctions by interstate unions and dominant countries to the main trade partners of Uzbekistan (Russian Federation) inevitable might bring the adverse effects to the economic potential of our country in the near future. This, in turn, indicates the possibility of the negative impacts and external threats to our economy in the future in the form of a decrease in external demand for export products of Uzbekistan.

Considering these challenges and threats, the President noted that "the most important priority is to further strengthen macroeconomic stability and maintain high rates of economic growth, including the balance of the State budget at all levels, the 
stability of the national currency, and the price level in the domestic market" [11].

In addition, to further transform the economic realities of our country and radically change the effectiveness of the economic policy being implemented, the Decree of the President of the Republic of Uzbekistan was adopted, a strategy of actions for the further development of the Republic of Uzbekistan was adopted, where one of the main priority areas where marked "Comprehensive and balanced socio-economic development of regions, districts, and cities, optimal and effective use of their potential"[1].

Naturally, these measures are aimed at improving the quality of economic growth, a stable and favorable improvement in the conditions for the private sector, the development of the institutional environment, the improvement of infrastructure and access to it, as well as the growth of the well-being of the population of our country, which in general will result from the level of local government, starting from districts and

$$
V_{i, r}^{t}=\frac{\Delta V A_{i}^{r}}{\Delta G R P^{r}} * 100=\frac{\left(V A_{i}^{t-1} * V A G R_{i}^{t}-V A_{i}^{t-1}\right)}{\left(G R P_{r}^{t-1} * G R P G R_{r}^{t}-G R P_{r}^{t-1}\right)} * 100,
$$

where,

$V_{i, r}^{t}$ - is the contribution of the i-industry of the r-region to the growth of the GRP of the rregion in the $t$-time period;

$V A_{i}^{t-1}$ - GVA of the $i$-industry of the r-region in the time period $t-1$, in current prices;

$V A G R_{i}^{t}$ - Real growth rate of GVA of the i-industry of the r-region in the $t$-time period;

$G R P_{r}^{t-1}$ - GRP of the r-region in the time period $t-1$, in current prices;

$G R P G R_{r}^{t}$ - Real growth rate of GRP of the r-region in the t-time period.

The results of the analysis show (see Picture 2) that among regions that achieved the highest GRP growth rates for 2000-2019 (Tashkent city 5.7 times, Jizzakh region 4.5 times, Andijan region 4.1 times, Republic Karakalpakstan 4.1 times, Samarkand 4.0 times, Namangan 3.9 times, and Surxondaryo regions 3.7 times), the main determinants of its economic growth were the industries and services.
Of the group of regions that have achieved the highest GRP growth rates, namely in the Jizzakh, Samarkand and Surkhandarya regions, one of the main determinants of economic growth is the agricultural sector, which has a downward trend. The service industries dominate the formation of economic growth in these regions. 
Picture-2. The contribution of industries to the growth of regional GRP for 2000-2019 (in\%)

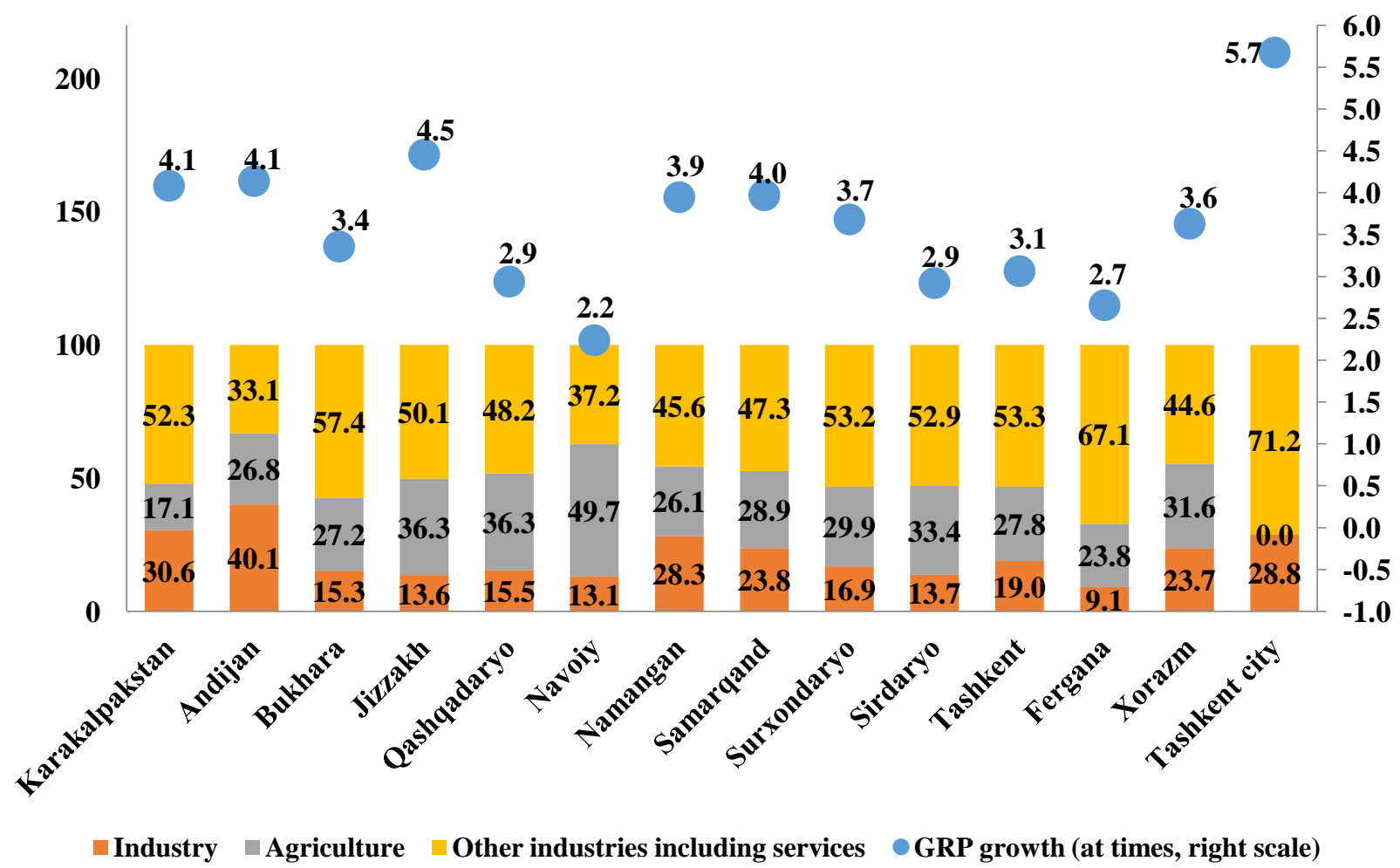

Source: Author's calculations based on data from the State Statistics Committee of the Republic of Uzbekistan. Data for 2000-2019 retrieved from the Statistical Yearbook.

The group of regions that have achieved moderate and low rates of economic growth of GRP, compared to the accumulated growth of the country's GDP (3.6 times) for the analyzed period, includes Khorezm (3.6 times), Bukhara (3.4 times), Kashkadarya (2, 9 times), Tashkent (3.1 times), Syrdarya (2.9 times), Fergana (2.7 times) and Navoi (2.2 times) regions.

The regions where the main determinant of economic growth was the agricultural sector had the lowest or moderate rates of economic growth of GRP over the analyzed period. The lowest GRP growth rate for the analyzed period is in the Navoi region (2.2 times), where the contribution of the agricultural sector to the GRP growth is more than $49.7 \%$.

Conclusion. Summarizing the results obtained on the analysis of structural transformations and the contribution of industries to the increase in the GRP of the regions of Uzbekistan, we can conclude that for the regions that fall into the groups with moderate and low rates of economic growth, it is advisable to significantly increase the contributions of industries and services in the short term to a counterbalance to the contribution of the agricultural sector. To achieve these goals, the regions need to develop effective measures through the adoption of medium-term strategies for the development of the economies of these regions, with an emphasis on stimulating the development of industries and services. 
A special place in the formation of the strategy should be given to short-term investment programs, where the main characteristics of projects should be the performance indicators of new and modernized production facilities, as well as ensuring broad participation of the private sector and small business in the implementation of these projects, which will entail a significant increase in the competitiveness of the products or services provided. which ultimately will serve as the foundation for the growth of the competitiveness of the region's economy and, as a result, will ensure high growth rates of the regions' GRP.

\section{CONCLUSION}

Another important result obtained from the analysis of the sectoral structure of the GRP of the administrative-territorial divisions of Uzbekistan and the contribution of industries to the growth of GRP for 2000-2019. the following specific phenomenon is observed. Some regions are lagging behind the regions in terms of economic growth, despite unambiguous structural shifts in the sectoral structure of GRP. For example, the situation in the Navoiy region can be cited. During the analyzed period, the Navoiy region is included in the group of regions that have achieved the most profound structural changes, however, in terms of the accumulated growth of GRP for the same period, it has the lowest values compared to other regions of Uzbekistan. The reasons for such conflicting results may lie in the transformation of the achieved structural changes into qualitative indicators of the economic growth of the regions. This provision, in turn, serves as a prerequisite for analyzing the quality of economic growth or the achieved qualitative changes in the economic development of the regions of Uzbekistan.

\section{REFERENCES}

1. Decree of the President of the Republic of Uzbekistan dated February 7, 2017 No.4947 "On the strategy of actions for the further development of the Republic of Uzbekistan";

2. Decree of the President of the Republic of Uzbekistan dated September 8, 2017 No.5185 “The concept of administrative reform in the Republic of Uzbekistan";

3. Decree of the President of the Republic of Uzbekistan dated August 8, 2017 No.3182 "On priority measures to ensure the accelerated socioeconomic development of regions";

4. Rakhmatullina A. D. The structure of the national economy: concept, essence, types // "Economy and Management", 2012, No. 2.

5. Abuzyarova M.I. Methodological foundations of structural changes in the economy // "Economics and Management", 2011, no. 4.

6. Rakhmatullina AD Assessment of structural changes in the regional economy. Abstract of the dissertation for the degree of candidate of economic sciences. Ufa-2013.

7. Decree of the President of the Republic of Uzbekistan dated December 15, 2010 No.1442 "On the priorities of industrial development of the Republic of Uzbekistan in 20102015";

8. Decree of the President of the Republic of Uzbekistan dated March 4, 2015 No.4707 "On the program of measures to ensure structural transformations, modernization and diversification of production for 20152019";

9. Resolution of the President of the Republic of Uzbekistan dated May 5, 2015 No.2343 "On the Program of Measures to Reduce Energy Intensity, 
Implementation of Energy Saving Technologies in the Sectors of the Economy and the Social Sphere for 2015-2019";

10. Resolution of the Cabinet of Ministers of the Republic of Uzbekistan dated January 5, 2016 No. 3 "On measures to further improve the procedure for the development of urban planning documentation for the development and construction of territories of cities and urban settlements";

11. 11. Mirziyoyev Sh.M. "Critical analysis, tough discipline and personal responsibility must become a daily routine in every leader's work". 